\title{
ANALISIS FAKTOR-FAKTOR YANG MEMPENGARUHI PILIHAN KARIR MAHASISWA FARMASI DI SEKOLAH TINGGI ILMU FARMASI RIAU
}

\author{
Erniza Pratiwi ${ }^{*}$, Fina Aryani ${ }^{1}$, Yulia Indri Yani ${ }^{1}$, \\ Ratna Sari Dewi $^{1}$, Tiara Tri Agustini ${ }^{1}$, Septi Muharni ${ }^{1}$ \\ ${ }^{1}$ Sekolah TinggiI lmu Farmasi (STIFAR) Riau \\ Jl. Kamboja Simpang Baru-Panam, Pekanbaru, 28928 \\ $1^{*}$ e-mail: ernizapratiwi@gmail.com
}

\begin{abstract}
ABSTRAK
Lapangan kerja atau prospek kerja dibidang farmasi sangatlah bervariasi, namun tenaga farmasi tersebut tidak terdistribusi secara merata. Tujuan dari penelitian ini adalah untuk menentukan faktor yang paling penting yang mempengaruhi pilihan karir dan arah pilihan mahasiswa serta melihat pengaruh data demografi terhadap faktor-faktor yang mempengaruhi pilihan karir mahasiswa. Jenis penelitian ini merupakan penelitian deskriptif analitik yang dilakukan dengan menggunakan survey. Teknik pengambilan sampel yang digunakan adalah stratified random sampel. Responden pada penelitian ini sebanyak 120 mahasiswa yang terdiri dari mahasiswa tingkat awal dan tingkat akhir di Sekolah Tinggi Ilmu Farmasi Riau. Dari hasil penelitian, secara keseluruhan mayoritas mahasiswa farmasi memilih berkarir di RumahSakit (RS) 34,2\%, disusul oleh Industri Farmasi 27,5\%, University/Research Institute 26,7\%, Pedagang Besar Farmasi (PBF) 5,8\% dan Apotek $5,8 \%$. Berdasarkan hasil analisis data univariat, terdapat 3 faktor yang sangat penting yang mempengaruhi pilihan karir mahasiswa adalah gaji/pendapatan, manfaat (benefits) dan lingkungan kerja. Dari hasil uji-t tidak berpasangan berdasarkan jenis kelamin, terdapat 3 faktor yang memiliki perbedaan yang bermakna yaitu faktor gaji/pendapatan, jadwal kerja fleksibel dan letak geografis, sedangkan antara mahasiswa tingkat awal dengan tingkat akhir tidak terdapat perbedaan yang bermakna dari setiap faktor-faktor yang mempengaruhi pilihan karir mahasiswa.
\end{abstract}

Kata Kunci: FaktorPemilihanKarir, PilihanKarir, MahasiswaFarmasi

ABSTRACT

Employment contract or prospects in the field of pharmacy are very variable, but the pharmacy staff are not evenly distributed. This is probably due to the factors that influence the career choice of a pharmacy worker. The aim of this study was to determine the main factor influencing the choice of career and student career choice direction and see the impact of demographic data on factors influencing students' career choices. This type of research is a descriptive analytical study conducted using a survey. The sampling technique used is a stratified random sample. The respondents in this study were 120 students, consisting of student class of 2014, 2015,2016 and 2017 at the School of Pharmacy Riau. From the survey, the vast majority of pharmacy students opted for a career in hospital (RS) $34.2 \%$, in one after another with $27.5 \%$ pharmaceutical industry, University / Research Institute 26.7\%, pharmaceutical wholesalers (PBF) 5.8\% and pharmacy 5.8\%. Based on the results of univariate data analysis, there are three very important factors that influence the career choices of students salary / income, (the benefits) and work environment. From the results of the unpaired t-test between male students and female there are three factors that have a significant difference, is a factor of salary / income, working hours flexible and geography, while in beginning students with the final level there is no significant difference of each factor factors that influence the choices of the student career.

Keywords: Career Choice Factor, Career Choice, Knowledge Factor, Pharmacy Student

\section{PENDAHULUAN}

Sumber daya manusia (SDM) merupakan salah satu faktor yang sangat penting dalam suatu perusahaan di samping faktor yang lain seperti modal. Sumber daya manusia harus dikelola dengan baik untuk meningkatkan efektivitas dan efisiensi organisasi, sebagai salah satu fungsi dalam perusahaan yang dikenal dengan manajemen sumber daya manusia (MSDM). Manajemen sumber daya manusia adalah perencanaan, pengorganisasian, pengarahan, pengawasan kegiatan-kegiatan pengadaan, pengembangan, pemberian kompensasi, pengintegrasian, pemeliharaan dan pelepasan sumber daya manusia agar tercapai tujuan organisasi dan masyarakat (Hariandja, 2002).

Sumber daya manusia kesehatan (SDMK) merupakan salah satu subsitem dalam system kesehatan nasional yang mempunyai peranan penting dalam mencapai tujuan pembangunan pelayanan kesehatan. Berdasarkan peraturan presiden nomor 72 tahun 2012 tentang sistem kesehatan nasional, sumber daya manusia kesehatan adalah tenaga kesehatan dan tenaga pendukung/penunjang kesehatan yang terlibat dan bekerja serta mengabdikan dirinya dalam upaya dan manajemen kesehatan.

Tenaga kesehatan dikelompokkan menjadi beberapa rumpun dan subrumpun. Rumpun tenaga kesehatan menurut undang-undang nomor 36 tahun 2014 tentang tenaga kesehatan pasal 11 adalah tenaga medis, tenaga psikologi klinis, tenaga keperawatan, tenaga kebidanan, tenaga kefarmasian, tenaga kesehatan masyarakat, tenaga kesehatan lingkungan, tenagagizi, tenaga keterampilan fisik, tenaga keteknisian medis dan lain-lain.

Badan pengembangan dan pemberdayaan sumber daya manusia kesehatan (BPPSDMK) 
setiap tahunnya mengumpulkan data SDMK berdasarkan tugas dan fungsi SDMK. Total SDMK di Indonesia pada tahun 2016 sebanyak 1.000.780 orang yang terdiri dari 736.077 orang tenaga kesehatan $(73,6 \%)$ dan 264.703 orang tenaga penunjang kesehatan $(26,4 \%)$. Proporsi tenaga kesehatan di bidang kefarmasian sebanyak 38.829 orang. Sedangkan proporsi kesehatan terbanyak yaitu tenaga keperawatan sebanyak $29,66 \%$ atau 296.876 orang. Dilihat dari data rekapitulasi ini jumlah tenaga kefarmasian lebih sedikit di bandingkan tenaga kesehatan lainnya (Anonim, 2017).Untuk tenaga apoteker di Provinsi Riau tahun 2016 berjumlah 352 orang. Jika dilihat dari penempatan tenaga apoteker di kabupaten/kota masih dominannya berada di daerahkotasepertikotaPekanbaru. Untuk tenaga teknis kefarmasian terdiri dari S-1 farmasi, D-III farmasi dan asisten apoteker di Provinsi Riau pada tahun 2015 memiliki rasio 11.7 per 100.000 penduduk. Rasio tenaga teknis kefarmasian berdasarkan kabupaten/kota rasio yang tertinggi ada pada kota Pekanbaru, sedangkan rasio terendah adalah Kabupaten Indragiri Hulu dan Kabupaten Indragiri Hilir (Anonim a , 2016).

Menurut peraturan pemerintah Republik Indonesia nomor 51 tahun 2009 tentang pekerjaan kefarmasian, dimana diterangkan bahwa pekerjaan kefarmasian adalah pembuatan obat termasuk pengendalian mutu sediaan farmasi, pengamanan, pengadaan, penyimpanan dan pendistribusian atau penyaluran obat, pengelolaan obat, pelayanan obat atas resep dokter, pelayanan informasi obat, serta pengembangan obat, bahan obat dan obat tradisional (Anonim, 2009). Lapangan kerja atau prospek kerja kefarmasian di Pekanbaru sangatlah beragam diantaranya yaitu rumah sakit, industri farmasi, pedagang besar farmasi, apotek dan lainlain, namun tenaga kefarmasian tersebut tidak terdistribusi secara merata. Hal ini kemungkinan terjadi karena adanya faktor-faktor yang mempengaruhi pilihan karir seorang tenaga kefarmasian.

Ada beberapa penelitian tentang faktor yang mempengaruhi pemilihan karir pada mahasiswa farmasi diantaranya yaitu penelitian oleh Pratiwi et al, (2017) tentang analisa faktor-faktor yang mempengaruhi pilihan karir mahasiswa farmasi di Universitas Andalas. Berdasarkan hasil analisa, faktor yang paling penting yang mempengaruhi pilihan karir mahasiswa farmasi adalah factor lingkungan kerja dengan pilihan karir utama adalah industry farmasi. Selanjutnya penelitian oleh Hasan et al, 2010 yang berjudul Influences on Malaysian Pharmacy Students' Career Preferences. Dari hasil penelitian ini faktor yang memiliki skor paling tinggi yaitu factor gaji dengan pilihan karir utamanya yaitu farmasi rumah sakit. Kemudian penelitian oleh Savage et al, 2009 yang berjudul Factor That Influence the Career Goals of Pharmacy Students. Mereka mengemukakan faktor yang paling penting dipertimbangkan oleh mahasiswa farmasi adalah lingkungan kerja sedangkan tujuan karir mahasiswa farmasi lima tahun setelah wisuda yaitu retail (chain).

Sekolah Tinggi Ilmu Farmasi Riau merupakan Yayasan Universitas Riau yang memprakarsai berdirinya perguruan tinggi bidang farmasi pada tahun 2002 dengan izin Mentri Pendidikan Nasional. Program studi yang dikembangkan yaitu program studi Strata satu (S1) dan Diploma tiga (DIII) denganakreditas B. Penelitian ini dilakukan di STIFAR karena satusatunyakampus yang menyelenggarakan program studiStaraSatu (S1) di Pekanbaru. Dilakukannya penelitian ini bertujuan untuk menentukan faktorfaktor yang paling penting yang mempengaruhi pemilihan karir mahasiswa dan untuk mengetahui arah pilihan karir serta melihat pengaruh data demografi terhadap faktor-faktor yang mempengaruhi pilihan karir mahasiswa di Sekolah Tinggi Ilmu Farmasi Riau yang akan dilakukan pada mahasiswa tingkat awal (angkatan 2016 dan 2017) dan mahasiswa tingkat akhir (angkatan 2014 dan 2015).

Manfaat dari penelitian ini yaitu yang pertama untuk menambah pengetahuan dan informasi bagi pihak peneliti sendiri untuk dapat lebih memahami persepsi mahasiswa farmasi dalam pemilihan karirnya, yang kedua sebagai bahan masukan bagi Sekolah Tinggi Ilmu Farmasi Riau untuk lebih meningkatkan kualitas pengajaran dengan harapan untuk lebih menghasilkan lulusanlulusan sarjana yang lebih berkualitas dan siap kerja, yang ketiga sebagai bahan masukan bagi lembaga farmasi yang mempekerjakan tenaga farmasi, sehingga mereka dapat mengetahui seperti apakah keinginan dan ekspektasi calon pekerja dalam memilih karirnya sebagai pekerja kefarmasian, manfaat yang terakhir yaitu sebagai referensi bagi peneliti selanjutnya yang ingin mengkaji masalah yang sama di masa depan.

\section{METODOLOGI PENELITIAN}

Penelitian ini menggunakan metode observasional dengan rancangan deskriptif analitik yang dilengkapi dengan kuesioner. Penelitian ini dilakukan pada bulan Juli sampai dengan Agustus 2018 di Sekolah Tinggi Ilmu Farmasi Riau. Metoda pengambilan sampel secara stratified random sampel yang terdiri dari 120 responden. Sampel pada penelitian ini adalah mahasiswa Sekolah Tinggi Ilmu Farmasi Riau angkatan 2014, 2015, 2016 dan 2017 yang memenuhi kriteria inklusi yakni mahasiswa yang masih aktif kuliah dan mahasiswa yang bersedia ikut serta dalam pengisian kuesioner. Sumber data pada penelitian ini adalah data primer dan data sekunder. Data primer merupakan kuesioner faktor-faktor pilihan karir yang sebelumnya telah dilakukan validasi, sedangkan data sekunder yaitu jumlah seluruh mahasiswa yang didapat dari data akademik di 
Sekolah Tinggi Ilmu Farmasi Riau. Data dianalisis menggunakan uji $\mathrm{T}$ Tidak Berpasangan terhadap data demografi.

\section{HASIL DAN PEMBAHASAN}

Tabel 1. Hasil Analisis Data Demografi Responden

\begin{tabular}{llcc}
\hline \multicolumn{1}{c}{ Uraian } & Kategori & $\begin{array}{c}\text { Frekuensi } \\
\text { (orang) }\end{array}$ & $\begin{array}{c}\text { Persentase } \\
(\%)\end{array}$ \\
\hline Jenis & Laki-laki & 20 & 16,7 \\
Kelamin & Perempuan & 100 & 83,3 \\
& 18 Tahun & 3 & 2,5 \\
& 19 Tahun & 25 & 20,8 \\
& 20 Tahun & 19 & 15,8 \\
& 21 Tahun & 29 & 24,2 \\
& 22 Tahun & 37 & 30,8 \\
& 23 Tahun & 4 & 3,3 \\
& 24 Tahun & 3 & 2,5 \\
\hline
\end{tabular}

Dalam penelitian ini ditemukan responden laki-laki hanya berjumlah 20 orang dengan nilai persentase sebesar $16,7 \%$ dan responden perempuan yang diperoleh yaitu 100 orang dengan nilai persentase sebesar $83,3 \%$. Hal ini kemungkinan disebabkan bahwa jurusan farmasi lebih banyak diminati oleh perempuan dibandingkan laki-laki. Selain itu menurut data Komite Farmasi Indonesia pada tahun 2015 lulusan Apoteker terbanyak adalah perempuan yaitu 3,363 orang sedangkan laki-laki hanya 1,070 orang (Anonim ${ }^{d}, 2014$ ), begitu juga denganpenelitian yang dilakukanolehPratiwiet al, 2017 dimana mahasiswa laki-laki hanya berjumlah 13 orang sedangkan mahasiswa perempuan berjumlah 72 orang. Dari data penerimaan mahasiswa baru di Sekolah Tinggi Ilmu Farmasi Riau tahun ajaran 2018/2019 bahwa mahasiswa yang lulus masuk ke Sekolah Tinggi Ilmu Farmasi Riau berjumlah 225 orang dengan jumlah mahasiswa perempuan sebanyak 199 orang, sedangkan mahasiswa lakilaki hanya berjumlah 26 orang, berdasarkan data ini menunjukkan bahwa jurusan farmasi lebih banyak diminati oleh perempuan.

Dari hasil data demografi responden menunjukkan persentase sebaran umur mahasiswa farmasi yaitu umur 18 tahun dengan nilai persentase $2,5 \%$, umur 19 tahun persentase $20,8 \%$, umur 20 tahun $15,8 \%$, umur 21 tahun $24,2 \%$, umur 22 tahun $30,8 \%$, umur 23 tahun $3,3 \%$ dan umur 24 tahun $2,5 \%$. Berdasarkan nilai persentase umur responden tersebut, menunjukkan bahwa umur responden tidak terlalu ada perbedaan yang signifikan. Umur bisa menentukan tingkat kedewasaan seseorang, sehingga hal ini bisa mempengaruhi dalam perilakunya dan cara pemikirannya.
Tabel 2. Hasil Anlisis Arah Pilihan Karir Mahasiswa

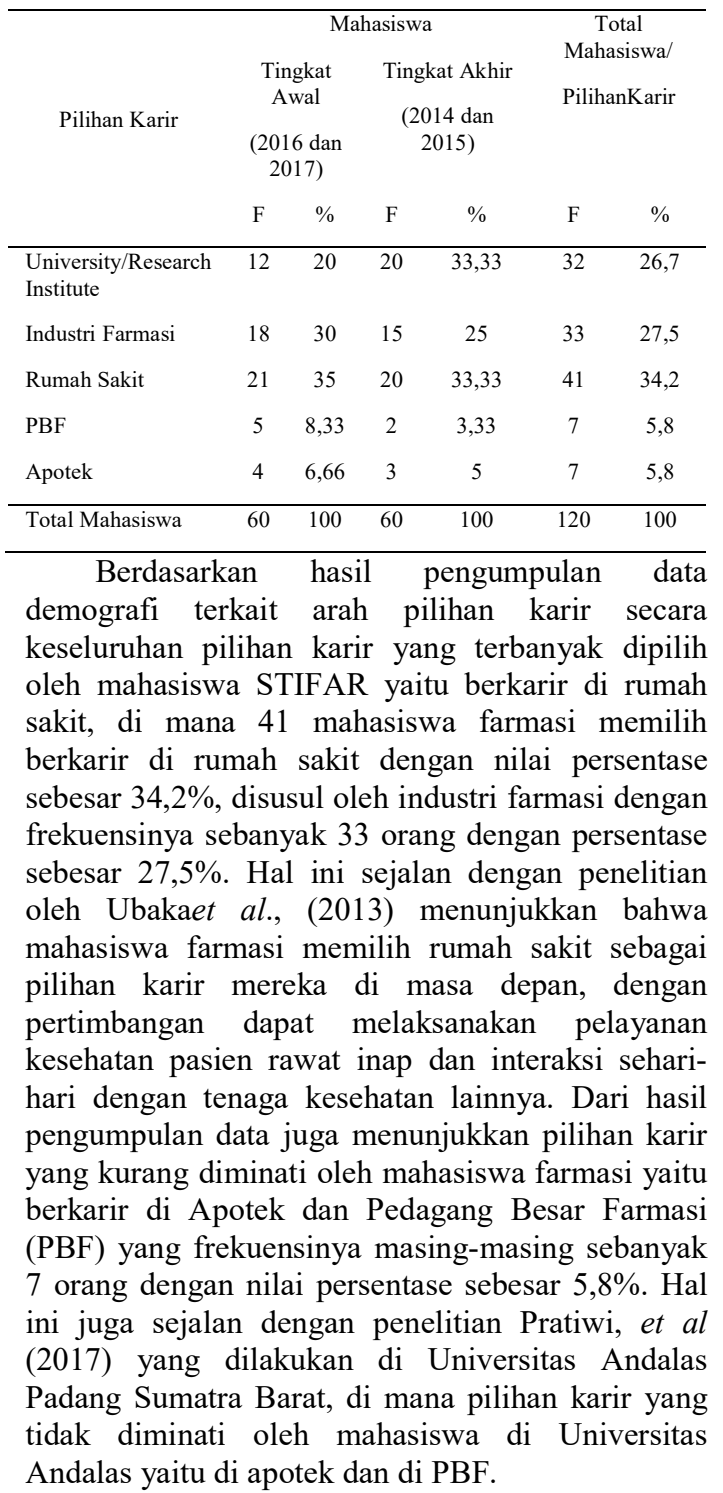

Tabel 3. Hasil Analisis Faktor-Faktor yang Mempengaruhi Pilihan Karir Mahasiswa Berdasarkan Skor Tingkat Capaian Responden (TCR)

\begin{tabular}{cccc}
\hline Variabel & $\begin{array}{c}\text { Rata- } \\
\text { rata } \\
\text { Skor }\end{array}$ & $\begin{array}{c}\text { Skor } \\
\text { TCR }\end{array}$ & $\begin{array}{c}\text { Interpretasi } \\
\text { Skor TCR }\end{array}$ \\
\hline $\begin{array}{c}\text { Gaji/Pendapatan } \\
\text { Jadwal Kerja }\end{array}$ & 4,67 & 93,4 & Sangat Penting \\
Fleksibel & 4,09 & 81,8 & Penting \\
Manfaat & 4,61 & 92,2 & Sangat Penting \\
Letak Geografis & 4,02 & 80,4 & Penting \\
Kesempatan & 4,48 & 89,6 & Penting \\
Berkembang & & & Sangat Penting \\
Lingkungan Kerja & 4,57 & 91,4 &
\end{tabular}


Berdasarkan nilai skor TCR faktor gaji/pendapatan berada pada urutan pertama sebagai faktor yang sangat penting dalam mempengaruhi pilihan karir seorang mahasiswa. Hasil penelitian ini didukung oleh penelitian yang dilakukan oleh Hasan et al., (2010) yang berjudul "Influences on Malaysian Pharmacy Students' Career Preferences", mengemukakan bahwa faktor gaji (salary) merupakan factor terpenting yang mempengaruhi pilihan karir seorang mahasiswa di masa depan. Menurut Samsudin (2009), gaji atau upah dapat diberikan kepada seorang karyawana yang didasarkan pada beberapa pertimbangan, yaitu diantaranya prestasi kerja, lama kerja, senioritas dan kebutuhan seseorang.

Faktor yang selanjutnya yaitu faktor manfaat (benefits) yang berada pada urutan kedua sebagai faktor yang dipertimbangkan dalam pilihan karir ke depan. dengan skor TCR (92,2\%). Hasil penelitian ini didukung oleh penelitian yang dilakukan oleh Savage et al, (2009) tentang Factors That Influence the Career Goals of Pharmacy Students, mengemukakan bahwa faktor manfaat berada pada urutan kedua dengan persentase sebesar 53,3\%, manfaat yang diperoleh dari institusi kerja sangat berperan penting dalam mempengaruhi pilihan karir. Pendapat responden terhadap manfaat didukung oleh hasil pertanyaan terbuka dimana menempatkan "fasilitas yang cukup" merupakan alas an bagi mereka dalam pemilihan karir mendatang.

Faktor yang berada pada urutan yang ke tiga yaitu faktor lingkungan kerja dengan skor TCR sebesar 91,4\%. Dari data dapat disimpulkan bahwa Mahasiswa Farmasi menginginkan lingkungan kerja yang aman, sehingga mereka dapat bekerja dengan baik dan optimal. Lingkungan kerja adalah sesuatu yang ada di lingkungan para pekerja yang dapat mempengaruhi dirinya dalam menjalankan tugas seperti temperatur, kelembapan, ventilasi, penerangan, kegaduhan, kebersihan tempat kerja dan memadai tidaknya alat-alat perlengkapan kerja.

Dari hasil penelitian juga menunjukkan 3 faktor yang termasuk kedalam kategori penting. Faktor yang pertama yaitu faktor jadwal kerja fleksibel dengan skor TCR yaitu $81,8 \%$.Schedule flexibility ini dilakukan karena dapat menciptakan lingkungan kerja yang positif, meningkatkan produktivitas kerja karyawan, meningkatkan kepuasan kerja dan komitmen kerja, mengurangi overtime, mengurangi tingkat absensi, mengurangi tingkat stress, mengurangi turnover dan menciptakan keseimbangan antara kehidupan pribadi karyawan dan kehidupan pekerjaan karyawan sehingga terjadi work-life balance (Carson et al, 2010).

Faktor yang kedua yang termasuk kedalam kategori penting yaitu faktor letak geografis dengan nilai skor TCR 80,4\%. Letak geografis yaitu letak suatu tempat dilihat dari kenyataan dimuka bumi atau letak suatu tempat dalam kaitannya dengan daerah lain disekitarnya. Letak geografis disebut juga letak relatif, disebut relatif karena posisinya ditentukan oleh fenomena-fenomena geografis yang membatasinya, misalnya gunung, sungai, lautan, benua dan samudera (Pratiwiet al, 2017).

Faktor yang ketiga yang termasuk kedalam kategori penting yaitu faktor kesempatan berkembang dengan skor TCR sebesar 89,6\%. Faktor peningkatan produktivitas salah satunya yaitu kesempatan berkembang dalam dunia kerja. Promosi (promotion) yaitu kemungkinan seseorang dapat berkembang melalui kenaikan jabatan. Seseorang dapat merasakan adanya kemungkinan yang besar untuk naik jabatan atau tidak, proses kenaikan jabatan kurang terbuka atau terbuka (Smith dan Hobin, 2006).

Tabel 4. Hasil Uji $\mathrm{T}$ Tidak Berpasangan Berdasarkan Jenis Kelamin

\begin{tabular}{|c|c|c|c|c|}
\hline Variabel & $\begin{array}{c}\text { Jenis } \\
\text { Kelamin }\end{array}$ & Mean & $\mathrm{P}$ & Interpretasi \\
\hline Gaji/Pendapatan & $\begin{array}{l}\text { Laki-laki } \\
\text { Perempuan }\end{array}$ & $\begin{array}{l}9,6500 \\
9,2900\end{array}$ & 0,037 & $\begin{array}{c}\text { Terdapat } \\
\text { perbedaan } \\
\text { signifikan }\end{array}$ \\
\hline $\begin{array}{l}\text { Jadwal Kerja } \\
\text { Fleksibel }\end{array}$ & $\begin{array}{l}\text { Laki-laki } \\
\text { Perempuan }\end{array}$ & $\begin{array}{l}15,3000 \\
16,5800\end{array}$ & 0,009 & $\begin{array}{c}\text { Terdapat } \\
\text { perbedaan } \\
\text { signifikan }\end{array}$ \\
\hline Manfaat & $\begin{array}{l}\text { Laki-laki } \\
\text { Perempuan }\end{array}$ & 18,5500 & 0,681 & $\begin{array}{c}\text { Tidak } \\
\text { terdapat } \\
\text { perbedaan } \\
\text { signifikan }\end{array}$ \\
\hline Letak Geografis & $\begin{array}{l}\text { Laki-laki } \\
\text { Perempuan }\end{array}$ & $\begin{array}{l}6,9000 \\
8,2700\end{array}$ & 0,006 & $\begin{array}{c}\text { Terdapat } \\
\text { perbedaan } \\
\text { signifikan }\end{array}$ \\
\hline $\begin{array}{l}\text { Kesempatan } \\
\text { Berkembang }\end{array}$ & $\begin{array}{l}\text { Laki-laki } \\
\text { Perempuan }\end{array}$ & 22,2500 & 0,672 & $\begin{array}{c}\text { Tidak } \\
\text { terdapat } \\
\text { perbedaan } \\
\text { signifikan }\end{array}$ \\
\hline Lingkungan Kerja & $\begin{array}{l}\text { Laki-laki } \\
\text { Perempuan }\end{array}$ & 22,7000 & 0,669 & $\begin{array}{c}\text { Tidak } \\
\text { terdapat } \\
\text { perbedaan } \\
\text { signifikan }\end{array}$ \\
\hline
\end{tabular}

Dari uji statistik tersebut ada beberapa variabel yang memiliki perbedaan yang signifikan berdasarkan jenis kelamin yaitu variabel gaji/pendapatan, jadwal kerja fleksibel dan letak geografis. Pada variabel gaji/pendapatan diperoleh nilai $\mathrm{p}=0,037(\mathrm{p}<0,05)$, di mana nilai ini lebih kecil dari $p=0,05$. Artinya terdapat perbedaan yang signifikan antara mahasiswa laki-laki dengan mahasiswa perempuan terhadap variabel gaji/pendapatan. Dilihat dari nilai rata-rata mahasiswa laki-laki $(9,65)$ lebih tinggi dari pada mahasiswa perempuan $(9,29)$. Hal ini kemungkinan terjadi karena perempuan beranggapan bahwa gaji merupakan hal yang tidak begitu penting, karena gaji yang mereka dapatkan hanya digunakan untuk keperluan dirinya sendiri, sedangkan laki-laki beranggapan bahwa gaji merupakan hal yang sangat penting, karena laki-laki memiliki tanggung jawab yang besar terhadap keluarganya dan laki-laki 
dituntut untuk dapat memenuhi kebutuhan seharihari atau finansial keluarga mereka.

Pada variabel jadwal kerja fleksibel didapatkan nilai $\mathrm{p}=0,009(\mathrm{p}<0,05)$, di mana nilai ini lebih kecil dari $\mathrm{p}=0,05$. Artinya terdapat perbedaan yang signifikan antara mahasiswa laki-laki dengan mahasiswa perempuan terhadap variabel ini. Dilihat dari nilai mean mahasiswa laki-laki $(15,30)$ lebih rendah dari pada mahasiswa perempuan $(16,58)$. Perbedaan ini kemungkinan terjadi karena perempuan cenderung memilih pekerjaan yang lebih mudah dikombinasikan dengan kehidupan berkeluarga dan dituntut untuk memberikan perhatian kepada keluarganya seperti kepada suamidanperanseorangibu (Gunarsa, 2000).

Variabel manfaat dilihat dari nilai $\mathrm{p}=0,681$ ( $p>0,05)$, di mana nilai $p$ lebih besar dari $p=0,05$, artinya tidak terdapat perbedaan yang signifikan antara laki-laki dan perempuan. Tidak ada nya perbedaan ini dapat dilihat dari nilai mean laki-laki yang hampir sama dengan nilai mean pada mahasiswa perempuan, sehingga dapat disimpulkan bahwa mereka memiliki persepsi yang sama yaitu mahasiswa laki-laki maupun mahasiswa perempuan ingin memberikan manfaat bagi masyarakat dan dapat memperoleh keseimbangan kerja dan kehidupan pribadi yang baik serta ingin memiliki posisi yang dihormati oleh orang lain.

Nilai $p$ pada variabel letak geografis yaitu sebesar $p=0,006(p<0,05)$, sehingga variabel ini memiliki perbedaan yang signifikan dimana nilai $p$ nya lebih kecil dari 0,05 . Dilihat dari nilai mean, mahasiswa perempuan nilai mean yang diperoleh sebesar $(8,27)$ sedangkan laki-laki sebesar $(6,90)$, sehingga dapat disimpulkan bahwa mahasiswa perempuan lebih mempertimbangkan letak geografis suatu institusi kerja. Jarak dari tempat tinggal pekerja ke tempat institusi kerja merupakan jarak yang harus ditempuh oleh seorang pekerja. Semakin jauh jaraknya maka waktu yang terbuang semakin banyak, tingkat efisiensi waktu menurun, sehingga curahan jam kerja akan semakin berkurang. Yang dimaksud dengan curahan waktu kerja adalah jumlah jam kerja yang dilakukan oleh pekerja untuk melakukan pekerjaan di institusi kerja, di rumah dan pekerjaan sambilan (Carlson, 2010).

Pada variabel kesempatan berkembang dan lingkungan kerja memilki nilai $\mathrm{p}$ besar dari 0,05 $(\mathrm{p}=>0,05)$ sehingga tidak terdapat perbedaan yang signifikan. Hal ini kemungkinan terjadi karena mahasiswa laki-laki dan perempuan memiliki pendapat yang sama terhadap kedua variabel ini. Mahasiswa mengharapkan berkesempatan untuk maju dan mengembangkan profesi mereka, selain itu mereka juga mengharapkan institusi tempat mereka bekerja memiliki kondisi kerja yang aman dengan memiliki fasilitas yang mendukung dalam jalannya pekerjaan. Institusi yang memilki kondisi yang aman akan menurunkan keinginan untuk berhenti bekerja di suatu institusi tersebut.

Setelah dilakukan analisis bivariat dengan menggunakan uji $\mathrm{T}$ Tidak Berpasangan untuk kelompok mahasiswa tingkat awal dan mahasiswa tingkat akhir terhadap faktor-faktor yang mempengaruhi pilihan karir mahasiswa diperoleh nilai $p$ besar dari $0,05 \quad(p>0,05)$ disetiap variabelnya. Artinya tidak terdapat perbedaan yang bermakna antara mahasiswa tingkat awal dan mahasiswa tingkat akhir terhadap faktor-faktor yang mempengaruhi pilihan karir mahasiswa.

Tabel 5. Hasil Uji $\mathrm{T}$ Tidak Berpasangan Berdasarkan Mahasiswa Tingkat Awal dan Tingkat Akhir.

\begin{tabular}{|c|c|c|c|c|}
\hline Variabel & Tingkat & Mean & $\mathrm{P}$ & Interpretasi \\
\hline \multirow[t]{2}{*}{ Gaji/Pendapatan } & Awal & 9,3333 & \multirow[b]{2}{*}{0,797} & \multirow{2}{*}{$\begin{array}{c}\text { Tidak } \\
\text { terdapat } \\
\text { perbedaan } \\
\text { signifikan }\end{array}$} \\
\hline & Akhir & 9,3667 & & \\
\hline \multirow{2}{*}{$\begin{array}{l}\text { Jadwal Kerja } \\
\text { Fleksibel }\end{array}$} & Awal & 16,3667 & \multirow[b]{2}{*}{1,00} & \multirow{2}{*}{$\begin{array}{c}\text { Tidak } \\
\text { terdapat } \\
\text { perbedaan } \\
\text { signifikan }\end{array}$} \\
\hline & Akhir & 16,3667 & & \\
\hline \multirow[t]{2}{*}{ Manfaat } & Awal & 18,4000 & \multirow[b]{2}{*}{0,723} & \multirow{2}{*}{$\begin{array}{c}\text { Tidak } \\
\text { terdapat } \\
\text { perbedaan } \\
\text { signifikan }\end{array}$} \\
\hline & Akhir & 18,4833 & & \\
\hline \multirow[t]{2}{*}{ Letak Geografis } & Awal & 8,0667 & \multirow[b]{2}{*}{0,838} & \multirow{2}{*}{$\begin{array}{c}\text { Tidak } \\
\text { terdapat } \\
\text { perbedaan } \\
\text { signifikan }\end{array}$} \\
\hline & Akhir & 8,0167 & & \\
\hline \multirow{2}{*}{$\begin{array}{l}\text { Kesempatan } \\
\text { Berkembang }\end{array}$} & Awal & 22,5833 & \multirow[b]{2}{*}{0,306} & \multirow{2}{*}{$\begin{array}{c}\text { Tidak } \\
\text { terdapat } \\
\text { perbedaan } \\
\text { signifikan }\end{array}$} \\
\hline & Akhir & 22,2167 & & \\
\hline \multirow[t]{2}{*}{ Lingkungan Kerja } & Awal & 22,8333 & \multirow[b]{2}{*}{0,923} & \multirow{2}{*}{$\begin{array}{c}\text { Tidak } \\
\text { terdapat } \\
\text { perbedaan } \\
\text { signifikan }\end{array}$} \\
\hline & Akhir & 22,8667 & & \\
\hline
\end{tabular}

Berdasarkan data diatas dapat dilihat bahwa nilai mean yang diperoleh di setiap variabelnya tidak berbeda jauh antara mahasiswa tingkat awal dengan mahasiswa tingkat akhir, sehingga dapat disimpulkan bahwa mahasiswa tingkat awal dengan mahasiswa tingkat akhir memiliki pertimbangan yang sama dalam memilih karir mereka ke depannya.

\section{SIMPULAN}

Berdasarkan penelitian yang dilakukan tentang analisis faktor-faktor yang mempengaruhi pilihan karir mahasiswa farmasi dari bulan Juli hingga bulan Agustus tahun 2018, dapat disimpulkan bahwa:

a. Faktor yang sangat penting yang mempengaruhi pilihan karir mahasiswa farmasi di Sekolah Tinggi Ilmu Farmasi Riau adalah faktor gaji/pendapatan (93,50\%), manfaat $(92,21 \%)$ dan lingkungan kerja $(91,40 \%)$. 
b. Arah pilihan karir utama mahasiswa farmasi di Sekolah Tinggi Ilmu Farmasi Riau adalah bekerja di rumah sakit dengan persentase $34,2 \%$ dan diikuti oleh industri farmasi dengan persentase $27,5 \%$.

c. Hasil Uji T Tidak Berpasangan menunjukkan bahwa terdapat perbedaan yang bermakna antara mahasiswa laki-laki dengan mahasiswa perempuan pada beberapa faktor yang mempengaruhi pilihan karir mahasiswa farmasi. Faktor-faktor tersebut antara lain yaitu faktor gaji/pendapatan dengan nilai $\mathrm{p}=0,037 \quad(\mathrm{p}<0,05), \quad$ faktor jadwal kerja fleksibel $p=0,009(p<0,05)$ dan faktor letak geografis $\mathrm{p}=0,006(\mathrm{p}<0,05)$.

d. Hasil uji T Tidak Berpasangan menunjukkan bahwa tidak terdapat perbedaan yang bermakna antara mahasiswa tingkat awal (angkatan 2016 dan 2017) dengan mahasiswa tingkat akhir (angkatan 2014 dan 2015) terhadap faktor-faktor yang mempengaruhi pilihan karir mahasiswa

\section{DAFTAR PUSTAKA}

Anonim, 2009, Peraturan Pemerintah Nomor 51 tahun 2009 tentang Pekerjaan Kefarmasian, Departemen Kesehatan RI: Jakarta.

Anonim, 2012, Peraturan Presiden Nomor 72 Tahun 2012 tentang Sistem Kesehatan Nasional, Departemen Kesehatan Republik Indonesia: Jakarta.

Anonima ${ }^{\text {a }}$ 2014, Undang-UndangRepublik Indonesia Nomor 36 Tahun 2014 Tentang Tenaga Kesehatan, Departemen Kesehatan Republik Indonesia: Jakarta
Anonim ${ }^{\text {, }}$ 2014, KomiteFarmasi Nasional Tahun 2014, diakses http://www.binfer-depkes.com, pada tanggal 20 Agustus 2018

Anonima, 2016, ProfilKesehatan Provinsi Riau 2016, DinasKesehatanProvinsi Riau: Pekanbaru

Anonim, 2017, Laporan Ketenagakerjaan Indonesia 2017, International Labour Organization: Jakarta.

Carlson, D.S., Grzywacz, G.j. danKacmar, K.M., 2010, The Relationship Of Schedule Flexibility and Outcome Via The Work-Family Interface, Journal of Managerial Psychology, 25(4): 330-335.

Gunarsa, 2000, PsikologiPraktis: Anak Remaja dan Keluarga, PT. BPK Gunung Mulia: Jakarta.

Hariandja, M.T.E., 2002, ManajemenSumberDayaManusia, PT GramediaWidiasarana Indonesia: Jakarta.

Hasan, S.S., Chong, D.W.K., Ahmadi,K., Se, W.P., Hassali, M.A., Hata, E.M., Hadi, M.A., Sridhar, S.B., Ahmed, S.I., Yean, L.B. danEfendie, B., 2010, Influences on Malaysian Pharmacy Student's Career Preferences, Am J Pharm Educ, 74(9): 166

Pratiwi, E., Putra, D.P. dan Syahrul, L., 2017, Analisis FaktorFaktor yang Mempengaruhi Pilihan Karir Mahasiswa Farmasi di Universitas Andalas, Fakultas Farmasi Universitas Andalas: Padang, JurnalPharmaciana 7(1): 51-62.

Samsudin, S., 2009, Manajemen Sumber Daya Manusia, Pustaka Setia: Bandung.

Savage, L.M. dan Beall, J.W., Woolley, T.W., 2009, Factors That Influence the Career Goals of Pharmacy Students. Am J Pharm Educ. 73(2): 28

Smith danHobin, 2006, ManajemenPersonalia, PT. Angkasa: Surabaya.

Ubaka, C.M., Ochie, U. M. danAdibe, M.O., 2013, Student Pharmacist's Career Choices: a Survey of Three Nigerian Schools of Pharmacy. Pharmacy Practice. 11(3): 149-155. 